This report was prepared as an account of work sponsored by an agency of the United States Government. Neither the United States Government nor any agency thereof, nor any of their employees, makes any warranty, express or implied, or assumes any legal liability or responsibility for the accuracy, completeness, or usefulness of any information, apparatus, product, or process disclosed, or represents that its use would not infringe privately owned rights. Reference herein to any specific commercial product, process, or service hy trade name, trademark, manufacturer, or otherwise does not necessarily constitute or imply its endorsement, recommendation, or favoring by the United States Government or any agency thereof. The views and opinions of authors expressed herein do not necessarily state or reflect those of the United States Government or any agency thereof.

\title{
SEMICONDUCTOR PROCESSING WITH EXCIMER LASERS
}

R. T. Young, J. Narayan, W. H. Christie,

G. A. van der Leeden, D. E. Rothe, and L. J. Cheng

\section{[Presented at the Winter ' 83 Topical Meeting on Excimer Lasers]}

By acceptance of this article, the publisher or recipient acknowledges the U.S. Government's right to retain a nonexclusive, rovalty-free license in and to any copyright covering the article.

\author{
SOLID STATE DIVISION \\ OAK RIDGE NATIONAL LABORATORY \\ Operated by \\ UNION CARBIDE CORPORATION \\ for the \\ U.S. DEPARTMENT OF ENERGY \\ Oak Ridge, Tennessee
}

January 798 ' 
SEMICONDUCTOR PROCESSING WITH EXCIMER LASERS*

$$
\begin{gathered}
\text { R. T. Young } \\
\text { Helionetics Inc. , San Diego, CA } 92123
\end{gathered}
$$

Oak Ridge National Laboratory, Oak Ridge, TN 37830

J. Narayan and $W$. H. Christie

Oak Ridge National Laboratory, Oak Ridge, TN 37830

\author{
G. A. van der Leeden ${ }^{+}$and D. E. Rothe \\ Helionetics Inc., San Diego, CA 92123 \\ and \\ L. J. Cheng \\ Jet Propulsion Laboratory, Pasadena, CA 91103 \\ ABSTRACT
}

The advantages of pulsed excimer lasers for semiconductor processing are reviewed. Extensive comparisions of the quality of annealing of ion-implanted Si obtained with $\mathrm{XeCl}$ and ruby lasers have been made. The results indicate that irrespective of the large differences in the optical properties of Si at UV and visible wavelengths, the efficiency of usage of the incident energy for annealing is comparable for the two lasers. However, because of the excellent optical beam quality, the $\mathrm{XeCl}$ laser can provide superior control of the surface melting and the resulting junction depth. Furthermore, the concentrations of electrically active point defects in the $\mathrm{XeCl}$ laser annealed region are 2-3 orders of magnitude lower than that obtained from ruby or Nd:YAG lasers. All these results seem to suggest that $X e C 1$ lasers should be suitable for fabricating not only solar cells but also the more advanced device structures required for VLSI or VHSIC applications.

\title{
INTRODUCTION
}

In the past few years, extensive research has been carried out on the use of laser radiation to process semiconductor materials. 1 The interest underiying this research is largely motivated by the realization that laser processing may have significant advantages over more conventional processing steps for the fabrication of many

\footnotetext{
*Research sponsored jointly by the Solar Energy Research Institute under contract BS-0-9078-1 and by the Division of Materials

Sciences, U.S. Department of Energy under contract W-7405-eng-26 with the Union Carbide Corporation.

+Present address: Guest Scientist, Solid State Division, Oak Ridge National Laboratory, Oak Ridge, TN 37830.
} 
semiconductor devices. Both pulsed and cw lasers have been used for laser processing. However, because of the difference in annealing mechanisms, i.e., liquid vs solid phase epitaxy, many properties such as dopant diffusion and segregation, the extent of grain growth in amorphous and polycrystalline material, and the concentrations of residual defects in the laser recrystallized region are quite different for pulsed and $\mathrm{cw}$ laser annealed samples. In this paper, we will concentrate our attention on the use of pulsed lasers for the annealing of ion-implanted silicon. More specifically, we will make extensive comparisons of the quality of annealing obtained with solid state lasers (ruby, YAG, etc.) and the recently developed rare gas halide excimer lasers (XeCl, KeF, etc.).

It is widely recognized that one of the major obstacles to the development of pulsed-litser processing for practical applications in the past has been the lack of suitable lasers. The pulsed lasers most commonly used for semiconductor processing have been ruby 10.694 $\mu \mathrm{m})$, frequency-doubled Nd:YAG $(0.532 \mu \mathrm{m})$ or glass $(0.531 \mu \mathrm{m})$, and (more recently) alexandrite $(0.700-0.818 \mathrm{\mu m})$ lasers. These solidstate lasers have certain limitations for high-throughput processing of large area devices. Foremost among these limitations is the spatial inhomogeneity of the energy density in the pulses. Inhomogeneities may be produced by a number of effects, e.g., multimode operation in which only a few modes are present, residual strains in the large solid-state laser rods, and thermal lensing. In addition, the coherent nature of the laser radiation may cause diffraction patterns to be produced by optical components, dust particles, and other sources of scattered radiation. Diffraction-related structure is frequently observed on surfaces irradiated with solid-state lasers. In order to reduce the pulse inhomogeneities to acceptable levels, it is necessary to transmit the beam through a beam homogenizer. Homogenization has been carried out using a variety of optical devices, including ground glass diffuser plates, bent quartz light pipes, and segmented cylindrical lens. These techniques produce either high transmission losses or interference fringes from the overlapping beams. Furthermore, the devices can only partially reduce the inhomogeneities, and they add to the complexity of the processing. 0ther drawbacks of solid-state lasers include low pulse repetition rates for systems with large diameter rods (because of the heat dissipation problem in the insulating crystals) and low overall energy conversion efficiency. These difficulties appear to put unacceptable limitations on device throughput rate and cost for many applications.

Gas lasers have few of the drawbacks of solid-state lasers, and it is now clear that the $\mathrm{XeCl}$ excimer laser used in our research has many of the characteristics needed for the efficient laser processing of semiconductors. Because of the large discharge volume and the short wavelengths involved, the optical cavity of a UV excimer laser can support oscillations of the eiectromagnetic field composed of a very large number of modes. A uniform beam with reduced spatial coherence is obtained and, as a result, interference effects caused by the coherent nature of normal laser radiation are nearly el iminated. This special characteristic of excimer lasers has been 
recent.ly demonstrated to be advantageous for UV 1 ithography, 2 and this same characteristic is highly desirable in the laser processing of semiconductor devices. Recent developments in excimer laser technology ${ }^{3}$ suggest that lasers with reasonably high energy per pulse and pulse repetition rates in the kilohertz range, or with single pulse output approaching $10^{3} \mathrm{~J}$, can be designed and constructed. The potential importance of these developments for the laser processing of materials is obvious, provided good spatial uniformity and pulse-to-pulse reproducibility can be maintained.

A careful and detailed evaluation of the suitability of excimer lasers for processing semiconductors, especially $\mathrm{Si}$, is necessary because of the large differences in the optical properties of silicon at $U V$ and visible wavelengths. 4 For example, the optical absorption coefficiert $\alpha$ of silicon at the $308 \mathrm{~mm}$ wavelength of the $\mathrm{XeCl}$ laser is $\sim 10^{6} \mathrm{~cm}^{-1}$ and the reflectivity $R$ is $260 \%$; neither quantity depends strongly on temperature. In contrast, the absorption coefficients for ruby and frequency-doubled $Y A G$ lasers are highly temperature dependent within the range $10^{3}-10^{5} \mathrm{~cm}^{-1}$, while $R=35-45 \%$ and is also somewhat temperature dependent. In spite of these large differences, we have found the quality of the annealing, in terms of removal of lattice damage, electrical activation of dopants, dopant profile behavior, and $p-n$ junction characteristics, to be very similar for the two types of lasers. 5 However, the extremely good spa$t i a]$ uniformity of the excimer laser beam, the reduced coherence of the radiation, and the wide energy window between the annealing and danage thresholds that results from these two characteristics, give excimer. lasers clear advintages over solid state lasers for many types of semiconductor piocessing. In fact, our results of recent studies using DLTS (deep level transient spectroscopy) on Schottky diodes shcy that the density of deep level defects in the excimer laser annzaled samples can be as low as $\sim 5 \times 10^{11} \mathrm{~cm}^{-3}$ which is about 2-3 orders of magnitude lower than the reported defect density in samples annealed by pulsed solid state lasers. 6 In our work, Si solar cells have been processed both by ruby and excimer lasers; the results indicate that XeCl laser processed cells generally givo superior performance.

\section{REVIEW OF PULSED LASER ANNEAL ING}

Before we present our experimental results, a brief review of the fundamentals of pulsed laser annealing and its potential applications will be given in this section. Even though solid state lasers (ruby or Nd:YAG) were used exclusively in this earlier work, the results to be demonstrated in the next section indicate that the annealing characteristics obtained with UV excimer lasers and solid state lasers are virtually the same. Therefore, all the features of pulsed laser annealing described here should be readily applicable to annealing with a XeCl laser.

Many research efforts to date in this area of solid state physics have been directed toward obtaining a fundamental understanding of pulsed laser induced ultrarapid surface melting and solidification. Both theoretical ${ }^{7}$ and experimental ${ }^{8}$ results indicate that in 
silicon the melt durations are typically in the range of a few tens to a fe'w hundreds of nanoseconds and the solidification rates are of the order of meters per second. In such melting and resolidification regimes, substantial dopant diffusion in the melt can occur and recrystallization takes place under conditions that are far from thermodynamic equilibrium. Manj phenomena such as nonequilibrium segregation, formation of superşaturated substitutional alloys, etc. have been observed and studied. 7 In spite of the nonequilibrium nature of the annealing process, high quality, dislocation-free, electrically active layers are readily produced. However, several reports ${ }^{6}$ have indicated that high densities of electrically active point defests smaller than the detection limit of TEM (transrission electron microscopy) are present in the annealed region. The origin of such defects was at first thought to be related to the ultrarapid quenching. However, such an hypothesis cannot be entirely correct because such high defect densities are not observed in excimer laser annealed samples. These results will be discussed later in this paper. Other than the use of pulsed lasers to remove ion implantation damage, potential applications include the use of laser radiation to induce dopant diffusion from solid, 9 iguid 10 and gaseous 11 sources, to dissolve second phase precipitates, 12 to produce supersaturated alloys, 13 to form metal silicides, $14^{\circ}$ to promote grain arowth, 15 to reduce sheet resistivity in polycrystalline Si, 16 to improve interface properties in Sos devices, 17 and to realize backsurface damage gettering. 18 Irrespective of so many potential applications, the device that has been fabricated most successfully so far by pulsed-laser annealing is the Si solar cell, 19 which can tolerate relatively large variations in the annealing energy density and does not have a complex surface structure. For the more complex structures, such as those used in the MOS devices of VLSI and VHSIC (very high speed integrated circuit) technologies, laser annealing is still in its infancy. The recent trend in integrated circuit development has been toward low-temperature processing, with the goals of obtaining shallower junction depth, higher operating speed, and increased packing density; it is believed by many device physicists that laser annealing may hold the key to the attainment of these goals. Processing areas associated with VLSI for which laser annealing has shown some encouraging results are 1) the reduction of the overlap capacitance in source-drain regions of short-channel MOSFET' $s$ as a result of the elimination of lateral diffusion effects 20,2$)$ the reduction of sheet resistance in polycrystalline Si to increase the conductivity of interconnects in poly-gate MOS structures, 16 and 3 ) the improvement of MOS recovery ?ifetime by laser back surface damage gettering. 18 These results, though encouraging, must still be considered preliminary because solid state lasers, with their inherent limitations, were used in the studies. Some of the questions which arise about the fabrication of complex devices with solid state lasers are 1) can the laser beam be controlled well enough to provide a particular junction depth to high accuracy (say $\pm 4 \%$ )? 2) Can the devices tolerate the electrically active defects introduced and/or remaining in the laser annealed region? 3) Can the problems associated with the simultaneous laser 
irradiation of different device areas composed of polysilicon, $\mathrm{SiO}_{2}$, and ion-implanted amorphous $S i$ be solved? 4) Can the processing give high enough throughput rates? It seems that, with the superior characteristics of excimer lasers, some of these problems encountered with solid state jasers may be easily resolved.

\section{EXPERIMENT}

An $x$-ray preionized, discharge-pumped $\mathrm{XeCl}$ laser designed and constructed by Helionetics, Inc. was used in the work reported here. The laser was designed so that the puise duration time $\tau_{\ell}$ can be varied between 20-90 nsec (FWHM, ntrapezoidal pulse) simply by changing the ratio of gas mixtures. The total area of the laser beam is $3 \mathrm{~cm} \times 2.5 \mathrm{~cm}$. The energy output is $22.5 \mathrm{~J}$ at $75 \mathrm{nsec}$, and the beam was focused to give the desired energy density. The pulse repetition rate of the present system is $1 \mathrm{~Hz}$, but an advanced laser system with $100 \mathrm{~Hz}$ repetition rate and pulse energy $>1 \mathrm{~J}$ is currently under construction. With this system, an annealing throughput of $250 \mathrm{~cm}^{2} \mathrm{sec}^{-1}$ should be possible. For comparison studies, a commercially available Apollo Q-switched ruby laser which gives an energy output of $212 \mathrm{~J}$ (multimode) and $\tau_{\ell}$ of $25 \mathrm{nsec}$ (FWHM, gaussian pulse) has beerı used in our work. Polished (100) Si samples implanted with As, B or Si at various energies to a dose up to $1 \times 10^{16} \mathrm{~cm}^{-2}$ were used in this study. All annealing was performed in air. No bean homogenizer was used during XeCl laser annealing, but a ground glass diffuser plate was used while annealing with the ruby laser. The depth of melting and crystal perfection of the laser regrown layers were determined by TEM. The dopant redistribution after laser annealing was examined by secondary ion mass spectroscopy (SIMS). The electrical properties of the laser-regrown layer were obtained from van der Pauw measurements and dark I-V characteristics. The electrically active defects were studied by DLTS. Laser-processed $\mathrm{Si}$ solar cells were fabricated by using a low-cost, gaseous-discharge implantation technique, followed by either ruby or excimer laser annealing, to form the front junction. The back surfaces were made degenerate by vacuum deposition of $\sim 70 \mathrm{~A}$ of antimony followed by laser annealing. $\mathrm{Ta}_{2} \mathrm{O}_{5}$ and $\mathrm{MgF}_{2}$ were used for doublelayer antireflection coatings.

IV. COMPARISON OF ANNEALING CHARACTERISTICS OF XECI AND RUBY LASERS

Surface Morphology

An important concern in the use of pulsed lasers in semiconductor processing is the surface morphology after laser treatment. The preservation of a flat, featureless surface is extremely important in devices if multi-step processing is required. Apart from hot spots and diffraction-induced loca] ized surface damage, a periodic surface structure has been observed 21 frequently in ruby or Nd:YAG laser annealed samples. This periodic pattern is thought to be due to heating by a standing wave resulting from the interference of the incident and the scattered wave. 22 Figures $1 \mathrm{a}$ and $1 \mathrm{~b}$ show typical surface structures observed after ruby laser annealing. A beam 

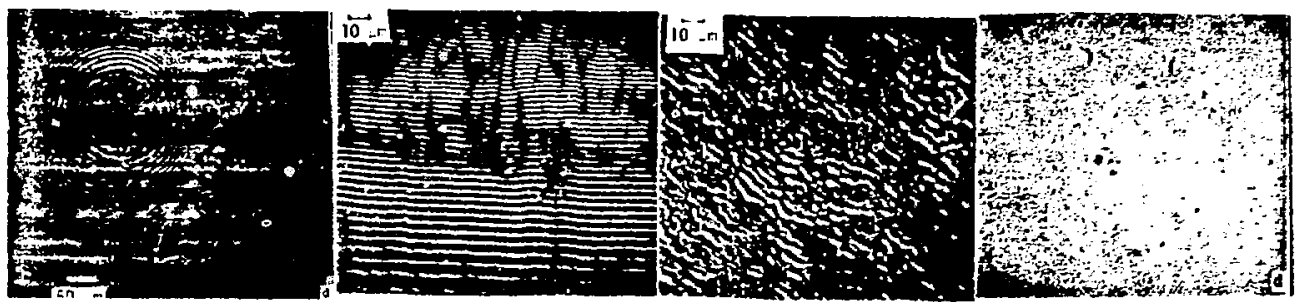

Fig. 1. Surface morphology of laser annealed Si surface.

a) EBIC image showing diffraction pattern and hot spots diractly from multimode beam of a ruby laser $\left(E_{\ell}=1.6 \mathrm{~J} / \mathrm{cm}^{2}\right)$,

b) optical micrograph showing periodic ripple structures directly from multimode beam of a ruby laser $\left(E_{\&}=1.8 \mathrm{~J} / \mathrm{cm}^{2}\right)$,

c) optical micrograph showing randomly distributed surface ripples from multimode beam of a ruby laser through a diffuser plate $\left(E_{\ell}=1.8 \mathrm{~J} / \mathrm{cm}^{2}\right)$,

d) optical micrograph showing the smooth surface directly from multimode beam of a Xecl laser $\left(E_{\ell}=3.5 \mathrm{~J} / \mathrm{cm}^{2}, \tau_{\ell}-55 \mathrm{nsec}\right)$.

homogenizer such as a ground glass diffuser plate can effectively remove the major intensity variations. However, the diffuser plate scatters most of the light into a relatively narrow cone about the incident beam direction and can produce focussing effects on a fine scale. This microfocussing can create randomly distributed surface ripples, as shown in Fig. 1c. These surface ripples can be eliminated only when the sample is placed farther from the diffuser with reduced energy density $\left(\leq 1.6 \mathrm{~J} / \mathrm{cm}^{2}\right)$. On the other hand, the surface morphology of the samples after XeCl laser annealing at energy densities up to $33-4 \mathrm{~J} / \mathrm{cm}^{2}$ (depending on the pulse duration time) is smooth and flat (Fig. 1d). No unusual surface features caused by hot spots, diffraction patterns or other interference effects are observed. To evaluate the uniformity of the laser beam on a microscopic scale, the damage interfaces in annealed and unannealed samples of B (200 kV) implanted Si were examined by TEM. Figure 2 shows cross section micrographs of samples annealed with the ruby laser through a diffuser plate and with the $X e C l$ laser at $2.5 \mathrm{~J} / \mathrm{cm}^{2}$. It is clearly seen that Xecl lasers provide a much more uniform interfacial layer. In contrast, a variation in melt depth as large as $225 \%$ in $2 \mu \mathrm{m}$ region is observed in ruby laser annealed sample.

Dopant Profiles

A comparison of laser-induced surface melting and dopant diffusion in ruby and XeCl laser-annealed samples of ${ }^{1} \mathrm{l}_{\mathrm{B}^{+}}(35 \mathrm{kV}$, $1 \times 10^{16} \mathrm{~cm}^{-2}$ ) implanted $S i$ was made by SIMS profiling. Both lasers had the pulse duration time of $225 \mathrm{nsec}$, although the pulse shapes were quite different. Figure 3 shows the dopant redistribution in samples annealed with the two lasers at energy densities of 1.5 $\mathrm{J} / \mathrm{cm}^{2}$ and $2.0 \mathrm{~J} / \mathrm{cm}^{2}$. It is interesting to see that at the same energy density, the resulting dopant profiles arising from the two lasers are almost identical. These results strongly suggest that 

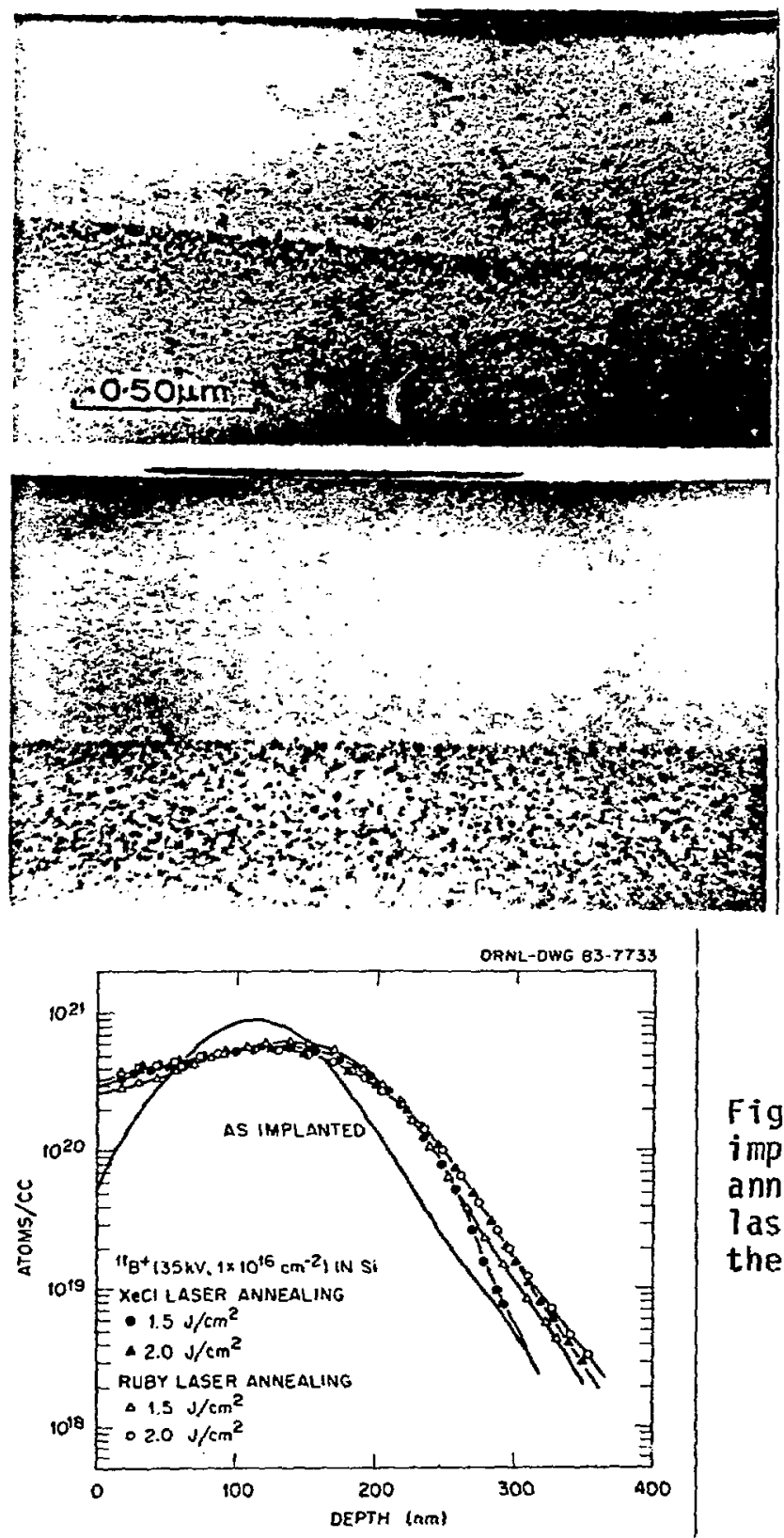

Fig. 2. TEM micrographs showing the annealed and unannealed damage interfaces in B (200 kV) implanted Si.
a) Ruby laser annealing at b) Xecl laser
annealing at
$2.5 \mathrm{~J} / \mathrm{cm}^{2}$.

Fig. 3. Comparison of boron implanted dopant profiles annealed at two different laser energy densities with the ruby and XeCl lasers.

regardless of the large differences in the optical properties of Si at UV and visible wavelengths, the efficiency of usage of the incident energy for melting Si surface regions to comparable depths is approximately the same for the two lasers with similar puise duration times. The quality of the annealing of these samp?es was subsequently examined by TEM and by van der Pauw measurements. In all cases, a dislocation-free, fully electrically activated laserregrown layer was observed. Because of the wide energy window in excimer laser annealing, deep junction profiles can be readily 
obtained with multiple pulses of laser radiation. This result is illusirated in Fig. 4. It shows that a sample with junction depth close to $0.9 \mu m$ can be achieved with 10 laser pulses at 3.5 $\mathrm{J} / \mathrm{cm}^{2}$ without any noticeable surface damage. Comparable junction depths could be obtained with ruby laser pulses, but the prevention of surface damage would be extremely difficult if not impossible.

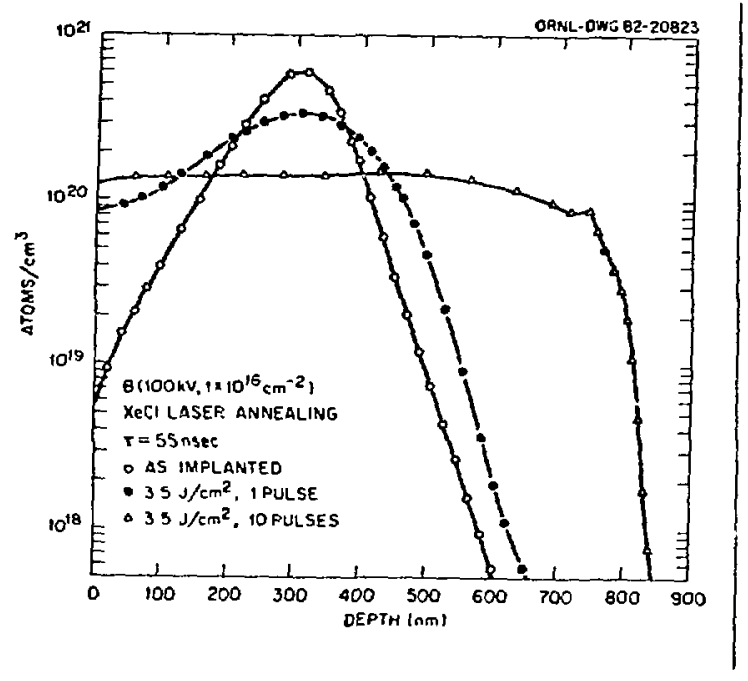

Fig. 4. SIMS profiles for boron in silicon after XeCl laser annealing at $3.5 \mathrm{~J} / \mathrm{cm}^{2}$ with 1 and 10 pulses.

Electrically Active Defects

The laser-annealed regions in our samples are dislocation-free under TEM observation and have good electrical properties (sheet resistivity and mobility) under van der Pauw examination, but as alroady mentioned, it has been reported ${ }^{6}$ that high concentrations (10 $13-10^{15} \mathrm{~cm}^{-3}$ ) of electrically active defects were detected by DLTS in samples irradiated with pulsed ruby and Nd:YAG lasers. Tine existence of these defects may have a large influence on device performance. In the study of $\mathrm{XeCl}$ laser annealed samples, we found that electrically active defects are present at concentrations much lower than those reported for samples annealed with solid state lasers. Figure 5 shows a typical DLTS spectrum from Schottky diodes made on $\mathrm{Si}\left(10 \mathrm{kV}, 5 \times 10^{15} \mathrm{~cm}^{-2}\right)$ implanted, B-doped silicon samples after XeCl laser (25 nsec) annealing at $2 \mathrm{~J} / \mathrm{cm}^{2}$. A single defect level located at $0.38 \mathrm{eV}$ above the energy of the valence band $E_{V}$ is observed. The concentration of this defect is $25 \times 10^{11} \mathrm{~cm}^{-3}$. These results strongly suggest that the existence of electrically active defects in laser regrown regions is not related solely to the regrowth velocity $V$, since meiting model calculations 23 show that the value of $V$ from the two lasers with the same pulse duration times are very similar. The mechanism of defect formation in sanples annealed with solid state lasers apparently needs considerable further study. 


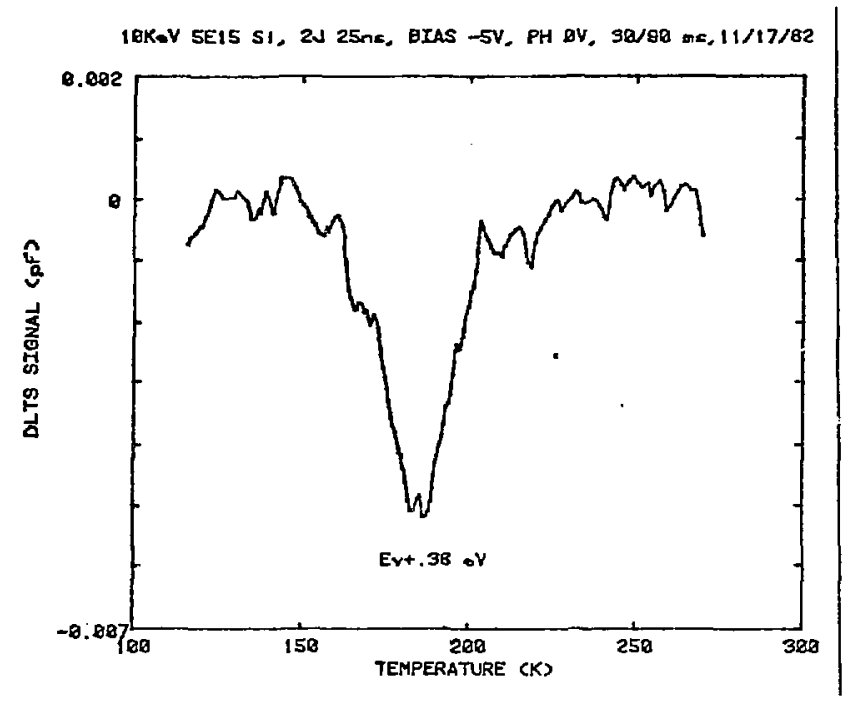

Fig. 5. DLTS spectrum of $\mathrm{Si}\left(10 \mathrm{kV}, 5 \times 10^{15}\right.$ $\left.\mathrm{cm}^{-2}\right)$ implanted p-type Si after XeCl laser annealing at $2.0 \mathrm{~J} / \mathrm{cm}^{2}$.

V. EFFECT OF PULSE DURATION ON THE ANNEALING

Advances in excimer laser technology indicate that, in addition to the capability for scaling, a laser system can be designed so that the pulse duration time $\tau_{2}$ can be adjusted over a range from ten to several hundred nsec. Variation of $\tau_{\ell}$ over this range with solid state lasers is difficult, if not impossible. Melting model calculations 7,23 show that, for the same energy density $E_{\ell}$, the depth of melting increases with decreasing pulse duration, especially for $E_{\ell}$ near the threshold for surface melting. The influerce of the regrcwth velocity on the quality of laser regrown layers and the optimum $\tau_{\ell}$ for energy-efficient semiconductor processing have not yet been investigated in detail.

In this section, we discuss the effect of $\tau_{\ell}$ on the annealing of ion-implanted $S i$ by comparing the melting depth, crystal perfection, dopant profiles, and electrical properties of samples annealed with a XeC1 laser with $E_{\ell}$ in the range of 0.5-3.0 J/ $\mathrm{cm}^{2}$ and for $\tau_{l}$ of 25 and 70 nsec. As anticipated from the model calculations, 23 the results indicated that $25 \mathrm{nsec}$ pulses are more energy efficient in annealing of ion-implanted damge than are $70 \mathrm{nsec}$ pulses. The melting depth as a function of laser energy density for the two laser pulses as determined from TEM is plotted in Fig. 6. It can be seen from the plot that at the same energy density, considerably deeper melting is achieved with $25 \mathrm{nsec}$ pulses than with $70 \mathrm{nsec}$ pulses, which is in good qualitative agreement with calculations. Figure 7 shows the effect of pulse duration time on the dopani profile redistribution of $100 \mathrm{kV} B$-implanted $S i$ annealed with $E_{q}=2.5$ and $3.0 \mathrm{~J} / \mathrm{cm}^{2}$; these results demonstrate that shorter laser pulses provide deeper dopant spreading, as expected. However, it is interesting to see that a very abrupt dopant profile was obtained on the sample that was annealed with $70 \mathrm{nsec}$ pulses at an energy density just above the threshold for complete annealing (i.e., $2.5 \mathrm{~J} / \mathrm{cm}^{2}$ in ihis case). Similar results ${ }^{5}$ were also observed in arsenic implanted 


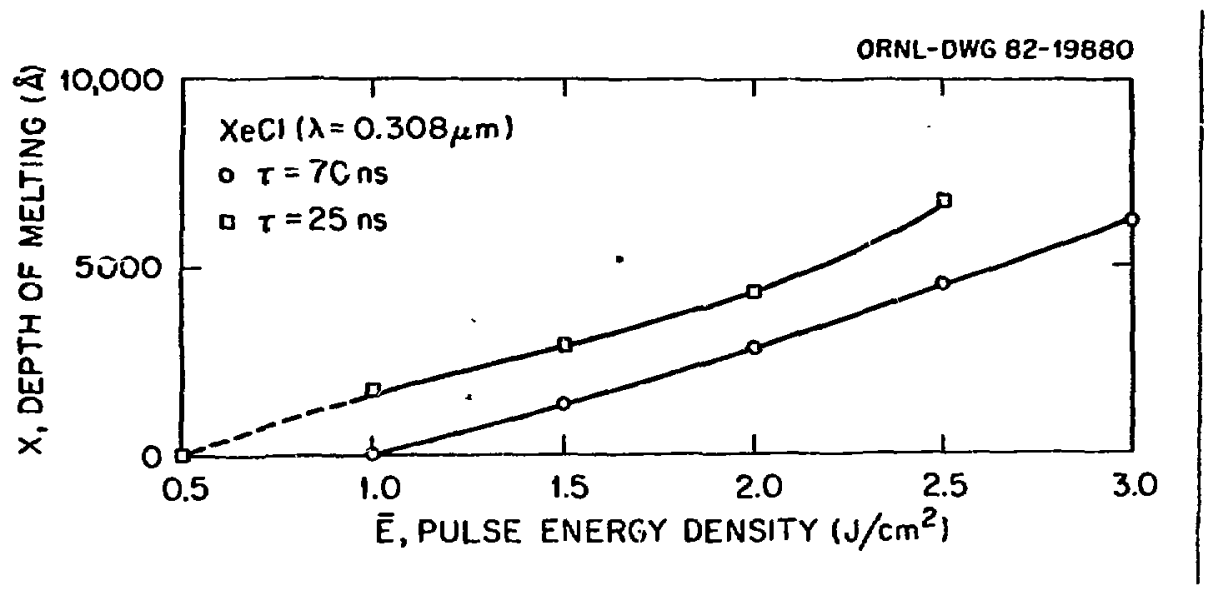

Fig. 6. The melting depth as a function of laser energy density for 25 and 70 nsec laser pulses as determined from TEM.

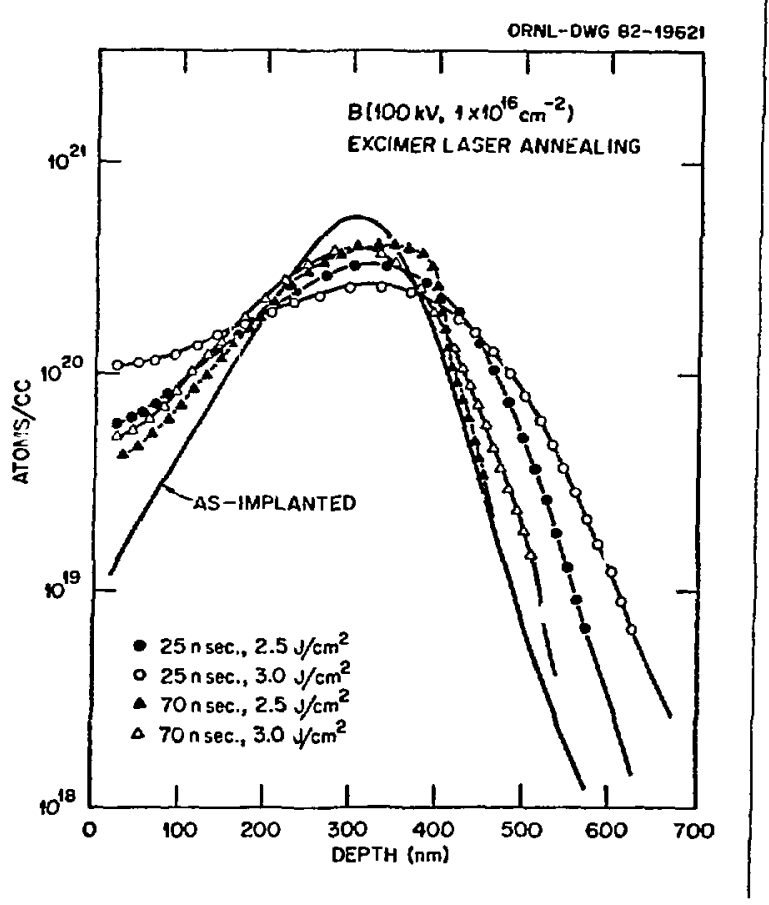

Fig. 7. A comparison of concentration profiles of $B$ in Si after $\mathrm{XeCl}$ laser annealing at 2.5 and 3.0 $\mathrm{J} / \mathrm{cm}^{2}$ with 25 and $70 \mathrm{nsec}$ pulses.

samples. This phenomenon has not been seen in ruby or short pulse $(25 \mathrm{nsec}) \mathrm{XeCl}$ laser annealed samples. The quality of annealing, in terms of crystalline perfection of the regrown layer (by TEM), junction characteristics (by dark I-V measurements), and residual defects (by DLTS), is very similar for the two pulse durations. Fron these results, we can conclude that for a device, in which a junction depth deeper than $21000 \mathrm{~A}$ is desired, a laser with shorter pulse duration is more energy efficient for annealing. However, longer pulse durations may have the advantage of providing shallow surface melting (200-500 A) and a more abrupt dopant profile, which 
is especially critical for high switching speed devices that require very sharp doping changes on the scale of $\approx 200 \mathrm{~A}$. Research related to this possibility is currently underway.

\section{EXCIMER LASER PROCESSED Si SOLAR CELLS}

Beam processing (ion or gaseous discharge implantation, laser or e-beam annealing) for solar cell prodiction is thought by many to be highly promising because of the expected ease of automation and the likely realization of improved control of a number of critical parameters (e.g., junction depth, sheet resistivity, lifetime), which will result in increased yield and improved cell performance. Recentily we have demonstrated that the combination of glow discharge implantation and $\mathrm{XeCl}$ excimer laser annealing for solar cell fabrication is especially suitable for terrestrial photovoltaic applications because of the potential for low cost and high throughput. 24 Polished 1-3 $\Omega-\mathrm{cm}$-type FZ Si wafers were implanted either by $\mathrm{BF}_{3}$ glow discharge implantation at an energy of $1 \mathrm{kV}$ to a dose of $6 \times 10^{15} \mathrm{~cm}^{-2}$ or with B by conventional ion implantation equipment at $5 \mathrm{kV}$ to the same dose. Each wafer was then cut into six $1 \times 2 \mathrm{~cm}$ samples. Half of the samples were annealed with the ruby laser and the other half with the excimer laser. The back surfaces were made degenerate by laser-induced diffusion of Sb. Evaporated $\mathrm{Ti}-\mathrm{Pd}-\mathrm{Ag}$ metallization was used to form the front and back contacts. Under optimum annealing canditions, all of the cells had open circuit voltages, $V_{O C}$ (measured at $28^{\circ} \mathrm{C}$ ) in the range $600-610 \mathrm{mV}$ and fill factors in the range 0.77-0.80. However, there were noticeable differences in the short circuit currents, $j_{S C}$. In general, tine excimer laser annealed cells showed better $J_{s c}$ than did the ruby laser annealed ones; whereas among the excimer laser annealed samples, the $\mathrm{BF}_{3}$ implanted cells had higher $\mathrm{J}_{\mathrm{sc}}$ than did the $\mathrm{B}(5 \mathrm{kV})$ implanted cells. This difference can be understood from internal quantum efficiency measurements on the cells before the application of AR
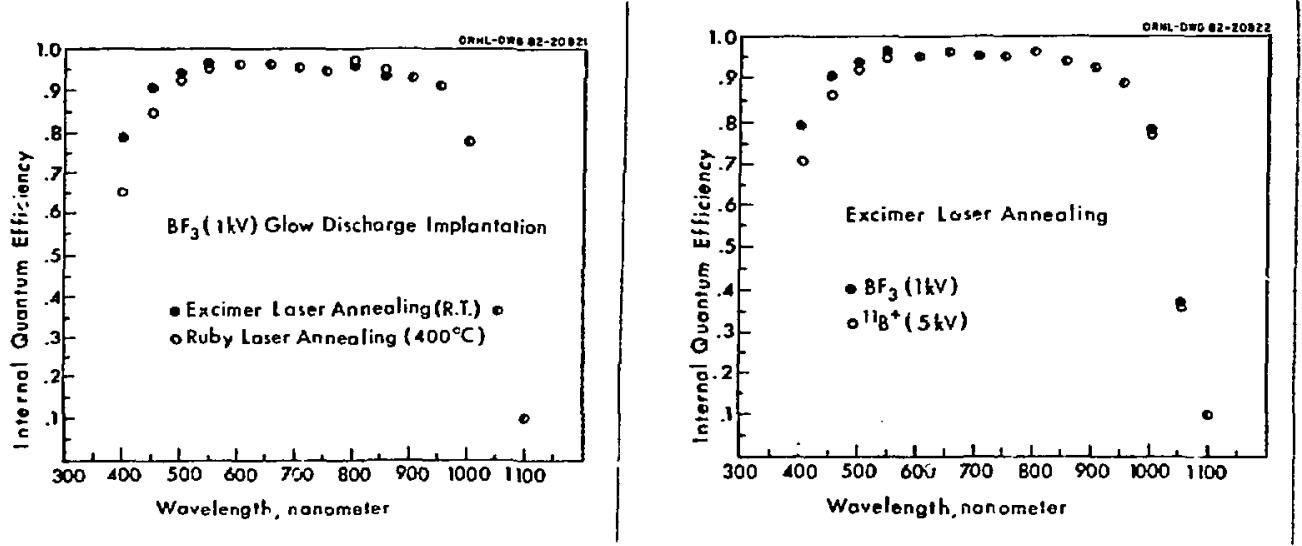

Fig. 8. Comparison of internal quantum efficiency between celis fabricated froin a) excimer and ruby laser annealing, and b) $\mathrm{BF}_{3}$ $(1 \mathrm{kV})$ and $1_{\mathrm{B}^{+}}(5 \mathrm{kV})$ implantation. 
coatings. The results, shown in Fig. 8, cleariy indicate that the $\mathrm{BF}_{3}$-implanted, exciwer laser-annealed cells have the highest blue response. This can be attributed to the high quality shallow junction formed from the shallow implantation ( $1 \mathrm{kV}$ ) and the extremely uniform annealing obtained with the excimer laser. The best discharge-implanted, excimer laser-annealed cell obtained so far has the parameters $V_{O C}=610 \mathrm{mV}, \mathrm{J}_{\mathrm{Sc}}=34.7 \mathrm{~mA} / \mathrm{cm}^{2}, \mathrm{FF}=0.79$, which result in an efficiency of $16.7 \%$. This efficiency is comparable to the highest efficiency Si solar cells made by the most sophisticated conventional methods.

\section{CONCLUSIONS}

We have demonstrated that regardless of the large differences in the optical properties of $\mathrm{Si}$ at the wavelengths of the radiation from a XeCl laser arid visible lasers such as ruby or frequencydoubled Nd:YAG, the efficiency of usage of the incident energy and the quality of annealing is very similar. However, because of the good optical qua? ity of the beam and perhaps because of the tranazoidal (rather than gaussian) temporal shape of the excimer laser pulses, excellent annealing with superior control of surface melting and the resulting junction depth can be obtained without the use of beam homogenizers and substrate heating. This provides important simp?ifications for application of laser annealing to device processing. We have demonstrated that high efficiency Si solar cells can be readily fabricated by laser processing. Furthermore, we found that the concentrations of elecirically active point defects, measured by DLTS, in the $\mathrm{XeC} 1$ laser-annealed regions are 2-3 crders of magnitude lower than those in regions annealed with solid state lasers. These features of $\mathrm{XeCl}$ lasers seem to suggest that this type of laser should be suitable for processing not only solar cells but also the more advanced device structures needed in VLSI and VHSIC applications.

\section{ACKNOWLEDGMENT}

The authors would like to thank R. F. Wood for his careful reading of the manuscript and helpful suggestions.

\section{REFERENCES}

1. See for example, R. T. Young and R. F. Wood, Ann. Rev. Mater. Sci., Vol. 12, 323 (1982).

2. K. Jain, C. G. Wilson, and B. J. Lin, IEEE Elect. Dev. Lett. EDL-3, 53 (1982).

3. D. E. Rothe, J. I. Levatter, R. L. Sandstrom, and P. B. Scott, Final Technical Repori, ONR Contract N00014-81C-0044, Helionetics, Inc., Laser Division, San Diego, CA, Jan., 1981.

4. G. E. Jellison, Jr., and F. A. Modine, J. Appl. Phys. $\underline{53}, 3742$ (1982). 
5. R. T. Young, G. A. van der Leeden, J. Narayan, W. H. Christie, R. F. Wood, D. E. Rothe, and J. I. Levatter, IEEE Elect. Dev. Lett. EDL-3, 280 (1982); D. H. Lowndes, J. H. Cleland, W. H. Christie, R. E. Eby, G. E. Jellison, Jr., J. Narayan, R. D. Westbrook, R. F. Wood, J. A. Nilson, and S. C. Dass, Appl. Phys. Lett. 41, 938 (1982).

6. See for example, K. C. Kimerling and J. L. Bentr,n in Laser and Electron Beam Processing of Materials, edited by C. W. White and P. S. Peercy (Academic Press, New York, 1980), p. 385; P. M. Mooney, R. T. Young, J. Karins, Y. H. Lee, J. W. Corbett, Phys. Status Solidi A 48, K31 (1981).

7. R. F. Wood and G. E. Gīles, Phys. Rev. B 23, 2923 (1981); R. F. Wood, J. R. Kirkpatrick, and G. E. Giles, Phys. Rev. B 23, 5555 (1981); R. F. Wood, Phys. Rev. B 25, 2786 (1982).

8. G. J. Galvin, M. 0. Thompson, J. W. Mayer, R. B. Hamriond, N. Paulter, and P. S. Peercy, Phy's. Rev. Lett. 48, 33 (1982).

9. J. Narayan, R. T. Young, and R. F. Wood, AppT. Phys. Lett. 33. 338 (1973).

10. R. Stucis, E. Fogarassy, J. C. Muller, M. Hodeau, A. Wattiaux, and P. Sittert, Appl. Phys. Lett. 38, 715 (1981).

11. G. B. Turner, D. Tarrant, G. Pollock, P. Pressley, and R. Press, Appi. Phys. Lett. 39,967 (1981).

12. R. T. Young and J. Narayan, App?. Phys. Lett. 33, 14 (1978).

13. C. W. White, S. R. Wilson, B. R. Appleton, and F. W. Young, Jr., J. Appl. Phys. 51,738 (1980).

14. J. M. Poate, H. J. Leamy, T. T. Sheng, G. K. Celler, Appl. Phys. Lett. 33,918 (i978).

15. R. F. Hood, R. T. Young, R. U. Westbrook, J. Narayan, W. H. Christie, and J. W. Cleland, Solar Cells 1, 145 (1980).

16. C. P. Wu and C. W. Magee, Appl. Phys. Let $\bar{t}$. 34, 737 (1979).

17. W. Luthy, K. Affolter, H. P. Weber, M. E. RoulTet, M. Fallavier, J. P. Thomas, and J. Mackowski, Appl. Phys. Lett. $\underline{35}, 873$ (1979).

18. L. E. Katz, P. F. Schmidt, and C. W. Pearce, J. Electrochem. Soc. $128,620(1981)$.

19. R. T. Young, R. F. Wood, and W. H. Christie, J. Appl. Phys. 53, 1178 (1982).

20. M. Kojanani, H. Tarmura, M. Miyao, N. Hashimoto, and T. Tokuyama, Appl. Phys. Lett. 35,621 (1979).

21. H. J. Leamy, G. A. Rozgonyi, T. T. Sheng, and G. K. Celler, Appl. Phys. Lett. 32, 535 (1978).

22. M. Oron and G. Sorensen, Appi. Phys. Lett. 35, 782 (1979).

23. R. F. Wood (private communication).

24. R. T. Young, G. A. van der Leeden, R. F. Wood, and R. D. Westbrook, Proceedings of the 16th IEEE Photovoltaic Specialists Conference, Sept. 27-30, 1982, San Diego, CA (to be published). 